\title{
OTTOCODIFICAÇÃO E ANÁLISE ALTIMÉTRICA E DA PRECIPITAÇÃO PLUVIOMÉTRICA DA BACIA HIDROGRÁFICA DO RIO CANOAS NA FRONTEIRA ENTRE O RIO GRANDE DO SUL E SANTA CATARINA
}

\author{
Fernanda Eimael Rolim ${ }^{1}{ }^{*}$, Yuri Timm Muller ${ }^{2}$, Franciso F. N. Marcuzzo ${ }^{3}$ \\ ${ }^{1,2}$ UFRGS/IPH - Instituto de Pesquisas Hidráulicas, 91501-970, Porto Alegre, Brasil. \\ ${ }^{3}$ CPRM-Serviço geológico do Brasil, 90840-030, Porto Alegre, Brasil.
}

*E-mail: fernanda.erolim@gmail.com

\section{RESUMO}

Elaborar uma boa analise em grandes bacias é um desafio, pois organizar um sistema de fácil entendimento para o pesquisador é viável criar procedimentos que discretizem a bacia hidrográfica. Neste contexto, o presente estudo teve por objetivo a ottocodificação da bacia hidrográfica do rio Canoas (sub-bacia 71) em dois níveis, utilizando a metodologia desenvolvida por Otto Pfafstetter no ano de 1989. Assim, essa metodologia nos permite elaborar uma análise direcionada e concisa da altimetria e dos volumes de precipitação. O procedimento teve suporte do programa computacional de SIG (Sistemas de Informações Geográficas), em especial ArcGIS 10.2, modelo digital de elevação SRTM, com resolução de 30m. Integralizando todas essas informações chegam-se a resultados de área, coordenadas geodésicas dos exutórios, como também os municípios e o rio principal de cada sub-bacia codificada. A sub-bacia ottocodificada com maior área é a 717, com aproximadamente $3.589,41 \mathrm{~km}^{2}$, classificada como de nível 1, e seu porcentual em relação a sub-bacia 71 é de $26,67 \%$, já em relação a sub-bacia ottocodificada de menor área é a 7185 classificada como de nível 2, apresenta uma área por volta de $3,06 \mathrm{~km}^{2}$ com um porcentual em relação a sub-bacia 71 de $0,02 \%$. Na totalidade foram delimitadas 90 sub-bacias, sendo que nove delas são de nível 1 e 81 classificadas como de nível 2.

Palavras-chave: Sub-bacia 71. Otto Pfafstetter. Bacia do rio Uruguai.

\section{Introdução}

A Lei das Águas estabelece a proteção da qualidade e quantidade dos recursos hídricos no território brasileiro, indicando a bacia hidrográfica como unidade de planejamento para atuação do Sistema Nacional de Gerenciamento de Recursos Hídricos através da Política Nacional de Recursos Hídricos, que prevê a definição de um sistema único de classificação e codificação das bacias hidrográficas brasileiras, para cada Estado e para o país. A Base Hidrográfica Ottocodificada (BHO) utilizada pela ANA na gestão de recursos hídricos é conseguida a partir do Mapeamento Sistemático Brasileiro. A BHO é gerada a partir da cartografia digital da hidrografia do país e organizada de modo à gerar informações hidrologicamente consistentes. Segundo Rosim et al.[21] o desenvolvimento de métodos que contribuam na construção da base de dados hidrográficos utilizando uma implementação computacional é uma importante ferramenta no processo de hierarquização das bacias hidrográficas, segundo sua área de contribuição e interações que descrevem a dinâmica da bacia. Nesse sentido, a ottocodificação de bacias possibilita a definição de uma posição relativa e o ordenamento entre as subbacias, o que contribui para que a modelagem computacional de processos hidrológicos tenha uma sequência a seguir em seus cálculos, conforme Buarque et al. [4].

O método de classificação e codificação de bacias hidrográficas desenvolvido por Pfafstetter [20] em 1989 é indicado, segundo Galvão e Meneses [8], para fins de planejamento de redes hidrométricas. Baseada na topografia da área drenada e na topologia da rede de drenagem (conectividade e direção) de aplicabilidade global e de fácil integração com os Sistemas de Informação Geográfica - SIG. A existência de uma deficiência de sistemas de aplicação global que indiquem, referenciem e identifiquem, de forma única a bacia hidrográfica, conforme elucidado por Silva [22], fomentou diversos estudos de aperfeiçoamento da metodologia desenvolvida por Pfafstetter, entre eles temos a tese de doutorado intitulada como "Ottocodificação estendida e inteligência hidrográfica em banco de dados geográficos" defendida por Teixeira [25] contribuindo para a gestão das águas. Os programas que possuem estrutura em SIG (Sistema de Informação Geográfica) têm capacidade de armazenamento, manipulação e análise de dados geográficos permitindo o cruzamento destes e a estimativa de cenários futuros, favorecendo o planejamento territorial e a gestão do meio ambiente, especialmente a gestão de bacias hidrográficas, segundo 
Marcuzzo, Cardoso et al. [17]. Vários outros trabalhos mostram a importância dos estudos de delimitação de bacias hidrográficas e da ottocodificação, como os desenvolvidos por Melati e Marcuzzo [19], Koefender e Marcuzzo [13], Goularte et al. [9] e Guimarães et al. [10].

Dessa forma, este estudo visou realizar a codificação da bacia do rio Canoas (sub-bacia 71) em dois níveis usando o sistema desenvolvido por Otto Pfafstetter em 1989, e estudar as diferenças da espacialização da chuva e altimetria na bacia.

\section{Material e Métodos}

\section{1 Área de estudo}

A bacia hidrográfica do rio Canoas é numerada como subbacia 71 pela classificação da Agência Nacional de Águas [1-2], citado por Marcuzzo [14-15], e possui área territorial aproximada de $13.461 \mathrm{~km}^{2}$ (área delimitada utilizando o modelo digital de elevação SRTM, com resolução de $30 \mathrm{~m}$ ). Considerando os dados do IBGE [11] da área territorial do Brasil, da região Sul e dos estados do Rio Grande do Sul $\left(256.175 \mathrm{~km}^{2}\right)$ e de Santa Catarina $\left(86.033,8 \mathrm{~km}^{2}\right)$, além da área da bacia do rio Uruguai $(349.844,10$ $\mathrm{km}^{2}$ ) segundo as publicação de Marcuzzo et al. [18]. A Figura 1 apresenta a localização e municípios da Bacia Hidrográfica do rio Canoas. Verifica-se que a bacia hidrográfica do rio Canoas (subbacia 71) representa $0,16 \%$ do território nacional, 2,6\% do território da região Sul, 15,6\% do território de Santa Catarina e $3,8 \%$ da bacia hidrográfica do rio Uruguai [18].

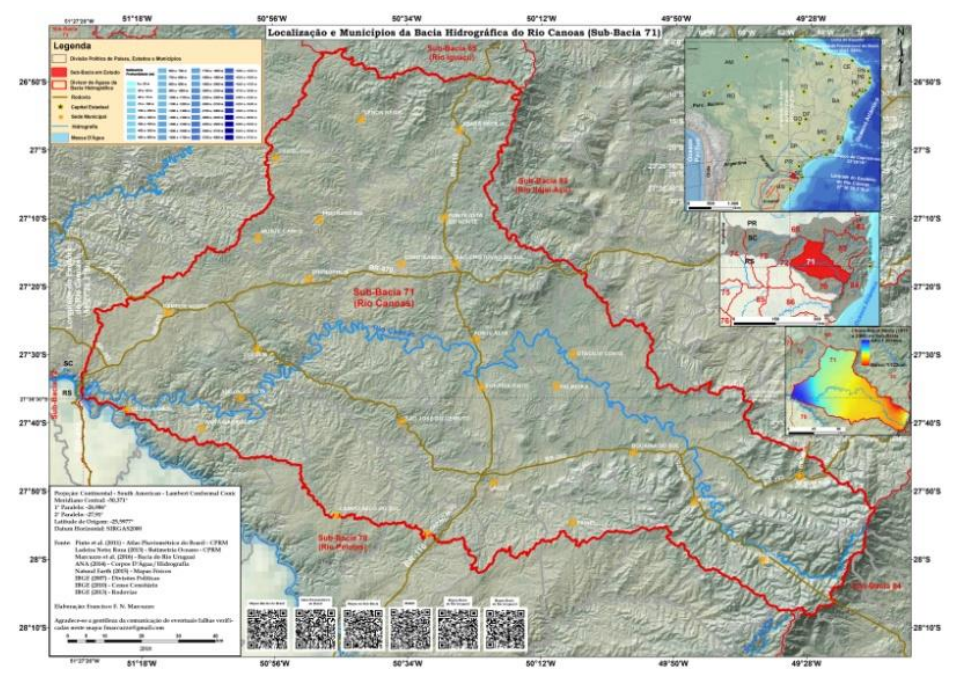

Figura 1 - Localização e municípios da bacia hidrográfica do rio Canoas (subbacia 71).

\subsection{Concepção da ottocodificação do rio Canoas}

O método de ottocodificação trata-se de uma hierarquização de bacias hidrográficas desenvolvida pelo engenheiro hidrológico Otto Pfafstette [20]. A motivação da criação deste método foi organizar os arquivos de projetos do antigo Departamento Nacional de Obras de Saneamento (DNOS), com o intuito de identificar as principais bacias do Brasil.

Na realização da ottocodificação da Bacia do rio Canoas utilizou-se um programa de SIG (Sistemas de Informações Geográficas) o ArcGIS 10.2 [7]. Neste programa contém diversas ferramentas das quais automatizam os procedimentos necessários para estudos relacionados aos recursos hídricos, como, por exemplo, a delimitação de bacias hidrográficas. Porém para a realização desde artigo, a ottocodificação foi realizada de maneira semiautomática, pois, os exutórios das sub-bacias foram inseridos manualmente. Segundo a apostila disponibilizada pela Agência Nacional de Águas [3], apresentada no Quadro 3, e conforme Teixeira [24], o primeiro procedimento necessário é identificar o curso d'água principal da bacia a ser codificada, que caracterizase por ser o rio principal, o qual recebe a maior contribuição de afluentes, segundo Collischonn e Dornelles [5]. Adotando o curso d'água principal como referência, determinam-se os quatro tributários com as maiores áreas de drenagem de jusante para montante, acrescentam-se os códigos 2, 4, 6 e 8 ao final do número 71, (sub-bacia do rio Canoas) para as quatro maiores bacias. As áreas restantes contribuem diretamente para o rio principal e são chamadas interbacias, os quais recebem então os dígitos ímpares $1,3,5,7$ e 9 .

\subsection{Cálculo da área de drenagem das sub-bacias ottocodificadas}

Para a geração da área de drenagem, utilizou-se o programa ArcGIS 10.2 [7], conforme já descrito por Melati Marcuzzo[19], em que utiliza o algoritmo de Jenson [12]. O programa define uma direção de fluxo para as células em direção a célula vizinha de maior declividade, como também faz o preenchimento de áreas de depressão onde os escoamentos convergem, possibilitando assim as operações hidrológicas. Assim, a delimitação e cálculo da área de drenagem da sub-bacia 71 e suas respectivas sub-bacias foi calculada utilizando o Modelo Digital de Elevação SRTM (Shuttle Radar Topography Mission) com aproximadamente 30 metros de resolução espacial, disponibilizados pela USGS (United States Geological Survey; Serviço Geológico dos Estados Unidos) sendo possível gerar um polígono do modelo digital de elevação para a área de interesse e fazer um mosaico [6]. Para o cálculo da área de drenagem utilizouse a projeção conforme de Lambert, a qual é a mais indicada para grandes bacias em médias latitudes. Dessa forma, essa projeção é classificada como cônica [23]. Para a delimitação da sub-bacia do rio Canoas utilizou-se as coordenadas geodésicas do exutório $51^{\circ} 27^{\prime} 11,5^{\prime \prime W}$ e $27^{\circ} 36 ' 28,5^{\prime \prime} \mathrm{S}$. As coordenadas geodésicas das demais sub-bacias geradas pelo método de Otto Pfafstetter para cada nível de ottocodifcação são apresentadas no Quadro 1 e 2. 


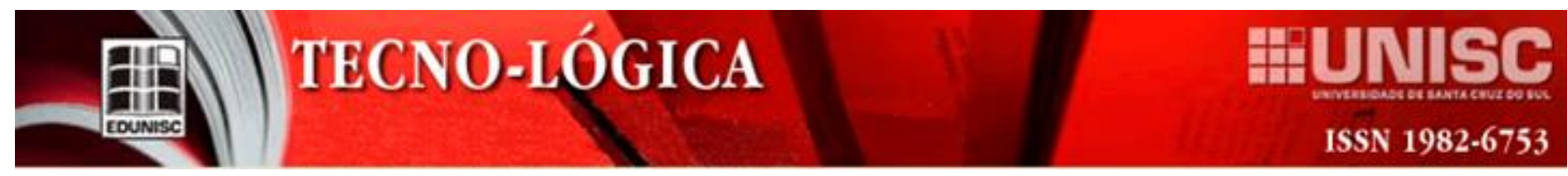

Quadro 1 - Coordenadas geodésicas para nível 1 de Ottocodificação da bacia do rio Canoas na bacia do rio Uruguai.

\begin{tabular}{|ccc|}
\hline \multirow{2}{*}{ Sub-Bacia } & \multicolumn{2}{c|}{ Coordenada geodésica } \\
\cline { 2 - 3 } & Longitude & Latitude \\
\hline 71 & $51^{\circ} 27^{\prime} 11,5^{\prime \prime} \mathrm{W}$ & $27^{\circ} 36^{\prime} 28,5^{\prime \prime} \mathrm{S}$ \\
711 & $51^{\circ} 27^{\prime} 11,5^{\prime \prime} \mathrm{W}$ & $27^{\circ} 36^{\prime} 28,5^{\prime \prime} \mathrm{S}$ \\
712 & $51^{\circ} 13^{\prime} 43^{\prime \prime} \mathrm{W}$ & $27^{\circ} 35^{\prime} 55^{\prime \prime} \mathrm{S}$ \\
713 & $51^{\circ} 13^{\prime} 43^{\prime \prime} \mathrm{W}$ & $27^{\circ} 35^{\prime} 55^{\prime \prime} \mathrm{S}$ \\
714 & $50^{\circ} 55^{\prime} 60^{\prime \prime} \mathrm{W}$ & $27^{\circ} 34^{\prime} 43^{\prime \prime} \mathrm{S}$ \\
715 & $50^{\circ} 55^{\prime} 60^{\prime \prime} \mathrm{W}$ & $27^{\circ} 34^{\prime} 43^{\prime \prime} \mathrm{S}$ \\
716 & $50^{\circ} 45^{\prime} 19^{\prime \prime} \mathrm{W}$ & $27^{\circ} 25^{\prime} 23^{\prime \prime} \mathrm{S}$ \\
717 & $50^{\circ} 45^{\prime} 19^{\prime \prime} \mathrm{W}$ & $27^{\circ} 25^{\prime} 23^{\prime \prime} \mathrm{S}$ \\
718 & $49^{\circ} 46^{\prime} 13^{\prime \prime} \mathrm{W}$ & $27^{\circ} 45^{\prime} 13^{\prime \prime} \mathrm{S}$ \\
719 & $49^{\circ} 46^{\prime} 13^{\prime \prime} \mathrm{W}$ & $27^{\circ} 45^{\prime} 13^{\prime \prime} \mathrm{S}$ \\
\hline
\end{tabular}

Quadro 2 - Coordenadas geodésicas para nível 2 de Ottocodificação da bacia do rio Canoas na bacia do rio Uruguai. (Continua)

\begin{tabular}{|c|c|c|}
\hline \multirow{2}{*}{ Sub-bacia } & \multicolumn{2}{|c|}{ Coordenada geodésica } \\
\hline & Longitude & Latitude \\
\hline 7111 & $51^{\circ} 27^{\prime} 11,5^{\prime \prime} \mathrm{W}$ & $27^{\circ} 36^{\prime} 28,5^{\prime \prime} \mathrm{S}$ \\
\hline 7112 & $51^{\circ} 25^{\prime} 45^{\prime \prime} \mathrm{W}$ & $27^{\circ} 34^{\prime} 29^{\prime \prime} \mathrm{S}$ \\
\hline 7113 & $51^{\circ} 25^{\prime} 15^{\prime \prime} \mathrm{W}$ & $27^{\circ} 34^{\prime} 1 " S$ \\
\hline 7114 & $51^{\circ} 21^{\prime} 15^{\prime \prime} \mathrm{W}$ & $27^{\circ} 36^{\prime} 5^{\prime \prime S}$ \\
\hline 7115 & $51^{\circ} 21^{\prime} 15^{\prime \prime W}$ & $27^{\circ} 36^{\prime} 5^{\prime \prime S}$ \\
\hline 7116 & $51^{\circ} 18^{\prime} 45^{\prime \prime} \mathrm{W}$ & $27^{\circ} 36^{\prime} 14^{\prime \prime S}$ \\
\hline 7117 & $51^{\circ} 18^{\prime} 45^{\prime \prime W}$ & $27^{\circ} 36^{\prime} 14^{\prime \prime S}$ \\
\hline 7118 & $51^{\circ} 15^{\prime} 51^{\prime \prime} \mathrm{W}$ & $27^{\circ} 37^{\prime} 60^{\prime \prime} \mathrm{S}$ \\
\hline 7119 & $51^{\circ} 15^{\prime} 26^{\prime \prime W}$ & $27^{\circ} 37^{\prime} 54^{\prime \prime S}$ \\
\hline 7121 & $51^{\circ} 13^{\prime} 43^{\prime \prime W}$ & $27^{\circ} 35^{\prime} 55^{\prime \prime} \mathrm{S}$ \\
\hline 7122 & $51^{\circ} 13^{\prime} 6^{\prime \prime} \mathrm{W}$ & $27^{\circ} 34^{\prime} 39^{\prime \prime S}$ \\
\hline 7123 & $51^{\circ} 13^{\prime} 6^{\prime \prime} \mathrm{W}$ & $27^{\circ} 34^{\prime} 39^{\prime \prime} \mathrm{S}$ \\
\hline 7124 & $51^{\circ} 11^{\prime} 24^{\prime \prime W}$ & $27^{\circ} 30^{\prime} 24^{\prime \prime S}$ \\
\hline 7125 & $51^{\circ} 11^{\prime} 24^{\prime \prime W}$ & $27^{\circ} 30^{\prime} 24^{\prime \prime S}$ \\
\hline 7126 & $51^{\circ} 3^{\prime} 46^{\prime \prime} \mathrm{W}$ & $27^{\circ} 24^{\prime} 6^{\prime \prime S}$ \\
\hline 7127 & $51^{\circ} 3^{\prime} 46^{\prime \prime} \mathrm{W}$ & $27^{\circ} 24^{\prime} 6^{\prime \prime S}$ \\
\hline 7128 & $51^{\circ} 1^{\prime} 23^{\prime \prime} \mathrm{W}$ & $27^{\circ} 20^{\prime} 16^{\prime \prime S}$ \\
\hline 7129 & $51^{\circ} 11^{\prime} 19^{\prime \prime} \mathrm{W}$ & $27^{\circ} 19^{\prime} 21^{\prime \prime S}$ \\
\hline 7131 & $51^{\circ} 13^{\prime} 43^{\prime \prime} \mathrm{W}$ & $27^{\circ} 35^{\prime} 55^{\prime \prime} \mathrm{S}$ \\
\hline 7132 & $51^{\circ} 12^{\prime} 46^{\prime \prime} \mathrm{W}$ & $27^{\circ} 37^{\prime} 10^{\prime \prime S}$ \\
\hline 7133 & $51^{\circ} 12^{\prime} 46^{\prime \prime} \mathrm{W}$ & $27^{\circ} 37^{\prime} 10^{\prime \prime} \mathrm{S}$ \\
\hline 7134 & $51^{\circ} 7 ' 26 " \mathrm{~W}$ & $27^{\circ} 37^{\prime} 12^{\prime \prime S}$ \\
\hline 7135 & $51^{\circ} 7 ' 26^{\prime \prime} \mathrm{W}$ & $27^{\circ} 37^{\prime} 12^{\prime \prime S}$ \\
\hline
\end{tabular}

Quadro 2- Coordenadas geodésicas para nível 2 de Ottocodificação da bacia do rio Canoas na bacia do rio Uruguai. (Continuação)

\begin{tabular}{|c|c|c|}
\hline \multirow{2}{*}{ Sub-bacia } & \multicolumn{2}{|c|}{ Coordenada geodésica } \\
\hline & Longitude & Latitude \\
\hline 7136 & $51^{\circ} 1 ' 23^{\prime \prime} \mathrm{W}$ & $27^{\circ} 38^{\prime} 30^{\prime \prime S}$ \\
\hline 7137 & $51^{\circ} 1 ' 23^{\prime \prime} \mathrm{W}$ & $27^{\circ} 38^{\prime} 30^{\prime \prime} \mathrm{S}$ \\
\hline 7138 & $50^{\circ} 57^{\prime} 32^{\prime \prime} \mathrm{W}$ & $27^{\circ} 38^{\prime} 47^{\prime \prime S}$ \\
\hline 7139 & $50^{\circ} 57^{\prime} 32^{\prime \prime} \mathrm{W}$ & $27^{\circ} 38^{\prime} 47^{\prime \prime S}$ \\
\hline 7141 & $50^{\circ} 55^{\prime} 60^{\prime \prime} \mathrm{W}$ & $27^{\circ} 34^{\prime} 43^{\prime \prime S}$ \\
\hline 7142 & $50^{\circ} 42^{\prime} 15^{\prime \prime} \mathrm{W}$ & $27^{\circ} 41^{\prime} 23^{\prime \prime S}$ \\
\hline 7143 & $50^{\circ} 42^{\prime} 15^{\prime \prime} \mathrm{W}$ & $27^{\circ} 41^{\prime} 23^{\prime \prime S}$ \\
\hline 7144 & $50^{\circ} 38^{\prime} 23^{\prime \prime} \mathrm{W}$ & $27^{\circ} 42^{\prime} 53^{\prime \prime S}$ \\
\hline 7145 & $50^{\circ} 38^{\prime} 23^{\prime \prime} \mathrm{W}$ & $27^{\circ} 42^{\prime} 53^{\prime \prime S}$ \\
\hline 7146 & $50^{\circ} 20^{\prime} 44^{\prime \prime} \mathrm{W}$ & $27^{\circ} 52^{\prime} 38^{\prime \prime S}$ \\
\hline 7147 & $50^{\circ} 20^{\prime} 44 " \mathrm{~W}$ & $27^{\circ} 52^{\prime} 38^{\prime \prime S}$ \\
\hline 7148 & $50^{\circ} 7^{\prime} 42^{\prime \prime} \mathrm{W}$ & $27^{\circ} 51^{\prime} 24^{\prime \prime} \mathrm{S}$ \\
\hline 7149 & $50^{\circ} 72^{\prime \prime} \mathrm{W}$ & $27^{\circ} 51^{\prime} 24^{\prime \prime S}$ \\
\hline 7151 & $50^{\circ} 55^{\prime} 60^{\prime \prime} \mathrm{W}$ & $27^{\circ} 34^{\prime} 43^{\prime \prime S}$ \\
\hline 7152 & $50^{\circ} 57^{\prime} 34 " \mathrm{~W}$ & $27^{\circ} 33^{\prime} 27^{\prime \prime} \mathrm{S}$ \\
\hline 7153 & $50^{\circ} 57^{\prime} 34^{\prime \prime} \mathrm{W}$ & $27^{\circ} 33^{\prime} 27^{\prime \prime S}$ \\
\hline 7154 & $50^{\circ} 54^{\prime} 23^{\prime \prime} \mathrm{W}$ & $27^{\circ} 32^{\prime} 2^{\prime \prime S}$ \\
\hline 7155 & $50^{\circ} 54^{\prime} 23 " \mathrm{~W}$ & $27^{\circ} 32^{\prime} 2^{\prime \prime S}$ \\
\hline 7156 & $50^{\circ} 48^{\prime} 36^{\prime \prime} \mathrm{W}$ & $27^{\circ} 29^{\prime} 54^{\prime \prime} \mathrm{S}$ \\
\hline 7157 & $50^{\circ} 48^{\prime} 36^{\prime \prime} \mathrm{W}$ & $27^{\circ} 29^{\prime} 54^{\prime \prime S}$ \\
\hline 7158 & $50^{\circ} 49^{\prime} 21 " \mathrm{~W}$ & $27^{\circ} 27^{\prime} 7^{\prime \prime S}$ \\
\hline 7159 & $50^{\circ} 49^{\prime} 21^{\prime \prime} \mathrm{W}$ & $27^{\circ} 27^{\prime} 7^{\prime \prime S}$ \\
\hline 7161 & $50^{\circ} 45^{\prime} 19^{\prime \prime} \mathrm{W}$ & $27^{\circ} 25^{\prime} 23^{\prime \prime} \mathrm{S}$ \\
\hline 7162 & $50^{\circ} 45^{\prime} 57^{\prime \prime} \mathrm{W}$ & $27^{\circ} 18^{\prime} 21^{\prime \prime S}$ \\
\hline 7163 & $50^{\circ} 45^{\prime} 57^{\prime \prime} \mathrm{W}$ & $27^{\circ} 18^{\prime} 21^{\prime \prime} \mathrm{S}$ \\
\hline 7164 & $50^{\circ} 42^{\prime} 11^{\prime \prime} \mathrm{W}$ & $27^{\circ} 11^{\prime} 20^{\prime \prime S}$ \\
\hline 7165 & $50^{\circ} 42^{\prime} 11^{\prime \prime} \mathrm{W}$ & $27^{\circ} 11^{\prime} 20^{\prime \prime S}$ \\
\hline 7166 & $50^{\circ} 42^{\prime} 41^{\prime \prime} \mathrm{W}$ & $27^{\circ} 6^{\prime} 8^{\prime \prime S}$ \\
\hline 7167 & $50^{\circ} 42^{\prime} 41^{\prime \prime} \mathrm{W}$ & $27^{\circ} 6^{\prime} 8^{\prime \prime S}$ \\
\hline 7168 & $50^{\circ} 39^{\prime} 30^{\prime \prime} \mathrm{W}$ & $27^{\circ} 5^{\prime} 15^{\prime \prime S}$ \\
\hline 7169 & $50^{\circ} 39^{\prime} 30^{\prime \prime} \mathrm{W}$ & $27^{\circ} 5^{\prime} 15^{\prime \prime S}$ \\
\hline 7171 & $50^{\circ} 45^{\prime} 19^{\prime \prime} \mathrm{W}$ & $27^{\circ} 25^{\prime} 23^{\prime \prime} \mathrm{S}$ \\
\hline 7172 & $50^{\circ} 29^{\prime} 24^{\prime \prime} \mathrm{W}$ & $27^{\circ} 27^{\prime} 39^{\prime \prime S}$ \\
\hline 7173 & $50^{\circ} 29^{\prime} 24 " \mathrm{~W}$ & $27^{\circ} 27^{\prime} 39^{\prime \prime S}$ \\
\hline 7174 & $50^{\circ} 16^{\prime} 2^{\prime \prime} \mathrm{W}$ & $27^{\circ} 31^{\prime} 57^{\prime \prime S}$ \\
\hline 7175 & $50^{\circ} 16^{\prime} 2^{\prime \prime} \mathrm{W}$ & $27^{\circ} 31^{\prime} 57^{\prime \prime} \mathrm{S}$ \\
\hline
\end{tabular}




\section{腈) TECNO-LÓGICA

Quadro 2- Coordenadas geodésicas para nível 2 de Ottocodificação da bacia do rio Canoas na bacia do rio Uruguai. (Conclusão)

\begin{tabular}{|c|c|c|}
\hline \multirow{2}{*}{ Sub-bacia } & \multicolumn{2}{|c|}{ Coordenada geodésica } \\
\hline & Longitude & Latitude \\
\hline 7176 & $50^{\circ} 7^{\prime} 13^{\prime \prime} \mathrm{W}$ & $27^{\circ} 31^{\prime} 24^{\prime \prime} \mathrm{S}$ \\
\hline 7177 & $50^{\circ} 7^{\prime} 13^{\prime \prime} \mathrm{W}$ & $27^{\circ} 31^{\prime} 24^{\prime \prime S}$ \\
\hline 7178 & $49^{\circ} 57^{\prime} 20^{\prime \prime} \mathrm{W}$ & $27^{\circ} 39^{\prime} 20^{\prime \prime} \mathrm{S}$ \\
\hline 7179 & $49^{\circ} 57^{\prime} 20^{\prime \prime} \mathrm{W}$ & $27^{\circ} 39^{\prime} 20^{\prime \prime} \mathrm{S}$ \\
\hline 7181 & $49^{\circ} 46^{\prime} 7^{\prime \prime} \mathrm{W}$ & $27^{\circ} 44^{\prime} 51^{\prime \prime S}$ \\
\hline 7182 & $49^{\circ} 39^{\prime} 18^{\prime \prime} \mathrm{W}$ & $27^{\circ} 47^{\prime} 20^{\prime \prime} \mathrm{S}$ \\
\hline 7183 & $49^{\circ} 39^{\prime} 18^{\prime \prime} \mathrm{W}$ & $27^{\circ} 47^{\prime} 20^{\prime \prime} \mathrm{S}$ \\
\hline 7184 & $49^{\circ} 33^{\prime} 51^{\prime \prime W}$ & $27^{\circ} 49^{\prime} 32^{\prime \prime S}$ \\
\hline 7185 & $49^{\circ} 33^{\prime} 51^{\prime \prime} \mathrm{W}$ & $27^{\circ} 49^{\prime} 32^{\prime \prime} \mathrm{S}$ \\
\hline 7186 & $49^{\circ} 32^{\prime} 30^{\prime \prime} \mathrm{W}$ & $27^{\circ} 49^{\prime} 42^{\prime \prime} \mathrm{S}$ \\
\hline 7187 & $49^{\circ} 32^{\prime} 30^{\prime \prime} \mathrm{W}$ & $27^{\circ} 49^{\prime} 42^{\prime \prime S}$ \\
\hline 7188 & $49^{\circ} 30^{\prime} 38^{\prime \prime} \mathrm{W}$ & $27^{\circ} 50^{\prime} 41^{\prime \prime S}$ \\
\hline 7189 & $49^{\circ} 30^{\prime} 38^{\prime \prime} \mathrm{W}$ & $27^{\circ} 50^{\prime} 41^{\prime \prime S}$ \\
\hline 7191 & $49^{\circ} 46^{\prime} 13^{\prime \prime} \mathrm{W}$ & $27^{\circ} 45^{\prime} 13^{\prime \prime S}$ \\
\hline 7192 & $49^{\circ} 46^{\prime} 38^{\prime \prime} \mathrm{W}$ & $27^{\circ} 45^{\prime} 32^{\prime \prime S}$ \\
\hline 7193 & $49^{\circ} 46^{\prime} 38^{\prime \prime} \mathrm{W}$ & $27^{\circ} 45^{\prime} 32^{\prime \prime S}$ \\
\hline 7194 & $49^{\circ} 43^{\prime} 9^{\prime \prime} \mathrm{W}$ & $27^{\circ} 53^{\prime} 9^{\prime \prime} \mathrm{S}$ \\
\hline 7195 & $49^{\circ} 43^{\prime} 9^{\prime \prime} \mathrm{W}$ & $27^{\circ} 53^{\prime} 9^{\prime \prime} \mathrm{S}$ \\
\hline 7196 & $49^{\circ} 35^{\prime} 40^{\prime \prime} \mathrm{W}$ & $27^{\circ} 58^{\prime} 25^{\prime \prime} \mathrm{S}$ \\
\hline 7197 & $49^{\circ} 36^{\prime} 1^{\prime \prime W}$ & $27^{\circ} 58^{\prime} 18^{\prime \prime S}$ \\
\hline 7198 & $49^{\circ} 32^{\prime} 26^{\prime \prime} \mathrm{W}$ & $27^{\circ} 59^{\prime} 33^{\prime \prime S}$ \\
\hline 7199 & $49^{\circ} 32^{\prime} 26^{\prime \prime} \mathrm{W}$ & $27^{\circ} 59^{\prime} 33^{\prime \prime S}$ \\
\hline
\end{tabular}

\section{Resultados e discussão}

No Quadro 3 encontra-se as Figuras com melhor resolução e as shapes produzidas na confecção deste trabalho. Também estão disponibilizados outros materiais de interesse utilizados neste artigo.

Quadro 3 - Figuras, com melhor resolução para visualização de detalhes deste estudo, e demais materiais para baixar. (Continua)

\begin{tabular}{|c|c|}
\hline & Endereços ("links") para Baixar Utilizando o Navegador de Internet \\
\hline Material & --- Mapas Para Impressão das Figuras Deste Trabalho em PDF (Folha A1) --- \\
\hline Figura 1 - Localização PDF & https://drive,google.com/file/d/1ZIp2TEbrkIYYOW5IMT8inedEainiu8qCR/view?usp=sharing \\
\hline Figura 1 - Localização PNG & htps://drive,google.com/file/d/ FeCHJKpiEwcarg9fo06b7HWN wscPvzOD/view?usp=sharing \\
\hline Figura 2-Ottocodificação Nível 1 PDF & 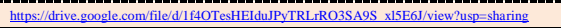 \\
\hline Figura 2- Ottocodificação Nível 1 PNG & https://drive.google.com/file/d/1281qAZdCH3h4JarYCFpinL06pd14KXAR/view?usp=sharing \\
\hline Figura 3 - Ottocodificação Nível 2 PDF & hitps://drive,google.com/file/d1 -r5SU02Sflb7ggeC7GKW65elgyz8UKO2/view2usp=sharing \\
\hline Figura 3-Ottocodificação Nível 2 PNG & 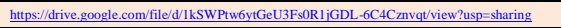 \\
\hline Figura 4-Chuva e Ottocodificação PDF & https://drive,google.com/file/d/1W7h__SpHbnZv-5SwCSQwWR8UzncdpHV9o/view?usp=sharing \\
\hline Figura 4-Chuva e Ottocodificação PNG & hitps://drive,google.com/file/d/144RFPz6WJcw0MfagiuSRhMTlibFcKiK/view?usp=sharing \\
\hline Figura 5 - Altimetria e Ottocodificação PDF & https://drive.google.con/file/d/1201Y HyEwkamWZZGleEGW1Hi5pLymFYJo/view?usp=sharing \\
\hline Figura 5 - Altimetria e Ottocodificação PDF & 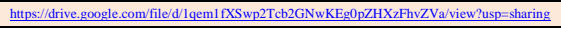 \\
\hline
\end{tabular}

Quadro 3 - Figuras, com melhor resolução para visualização de detalhes deste estudo, e demais materiais para baixar. (Conclusão)

\begin{tabular}{|c|c|}
\hline & ----- Material de Interesse Utilizado e/ou Produzido Neste Trabalho ------ \\
\hline Shape Ottocodificação Nível 1 & hitps://drive.google.com/drive/folders/LDE4tX8HN7zTNOWKB6Xbo7KvgyAilv_c?ogsrc=32 \\
\hline Shape Ottocodificação Nível 2 & https://drive.google.com/drive/folders/lquwoHVwEYV8cLfffHWRSwPvEOL8yac-bG?ogsrc=32 \\
\hline Mapas das bacias hidrográficas do Brasil & https://drive,google.com/folderview?id=0B5YK_fCaGOyyblFrVIImSXB3ZUE\&usp=sharing \\
\hline Mapas da bacia hidrográfica do Rio Uruguai & hitps://drive.google.com/drive/folders/0B5YK _fCaGOyfoiB3dDR4emh6YXc?usp=sharing \\
\hline Atlas Pluviométrico do Brasil & 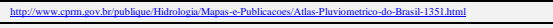 \\
\hline Material ANA - "Codificação De Bacias"'”' & https://capacitacao.ead.unesp.br/dspace/bitstream/ana/104/1/apostila.pdf \\
\hline
\end{tabular}

\subsection{Ottocodificação}

Neste estudo foi realizada a ottocodificação em dois níveis para a bacia do rio Canoas. A Figura 2 (nível 1) e a Figura 3 (nível 2). Para cada nível foi calculada a área de drenagem e o percentual de cada sub-bacia em relação a bacia do rio Canoas, assim como a localização do rio principal. Nota-se pelos resultados apresentados nos Tabela 1 e Tabela 2 os percentuais de área em relação ao total da área da sub-bacia 71 são maiores para o nível 1 de ottocodificação em comparação ao nível 2. Nota-se que a maior área em relação a classificação de nível 1 é a sub-bacia ottocodificada 717 apresentando uma área de $3589,41 \mathrm{~km}^{2}$ com um porcentual de $26,67 \%$ em relação a sub-bacia 71 , o seu rio principal é o rio Canoas, as cidades representativas desta maior sub-bacia são Chapadão do Lageado e Palmeiras conforma o Quadro 6. Faz-se a mesma análise para o nível 2 de ottocodificação tem-se a sub-bacia 7164 com área de $10,88 \mathrm{~km}^{2}$ com um porcentual de $8,09 \%$, o rio que recebe a maior contribuição é o rio Marombas, os municípios que englobam esta localidade são Taió e Santa Cecília (Quadro 5).

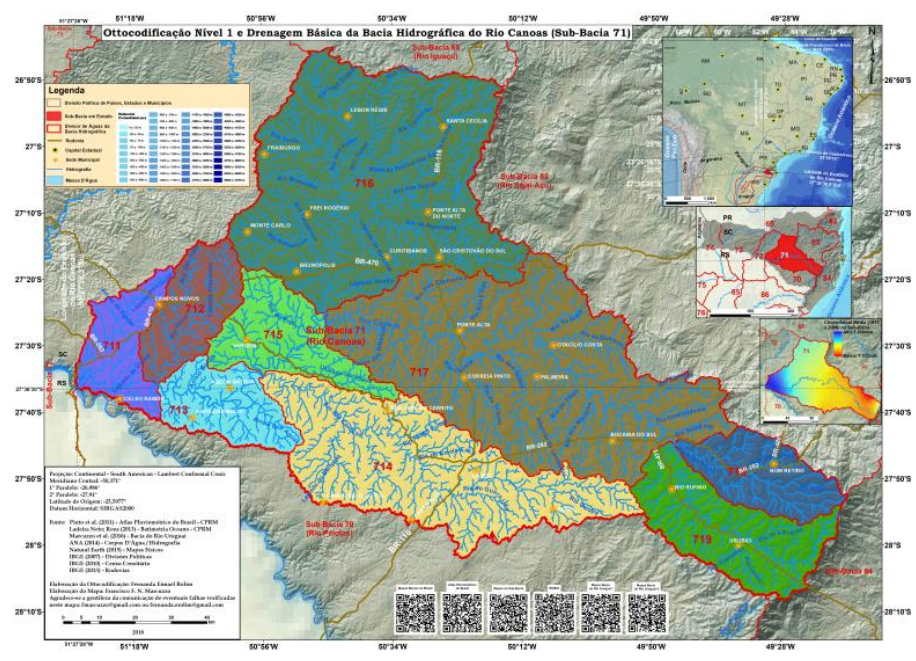

Figura 2 - Ottocodificação nível 1 e drenagem básica da bacia hidrográfica do rio Canoas (sub-sacia 71) 


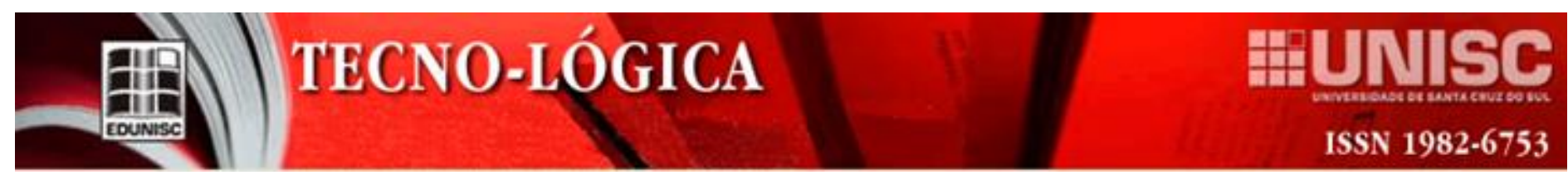

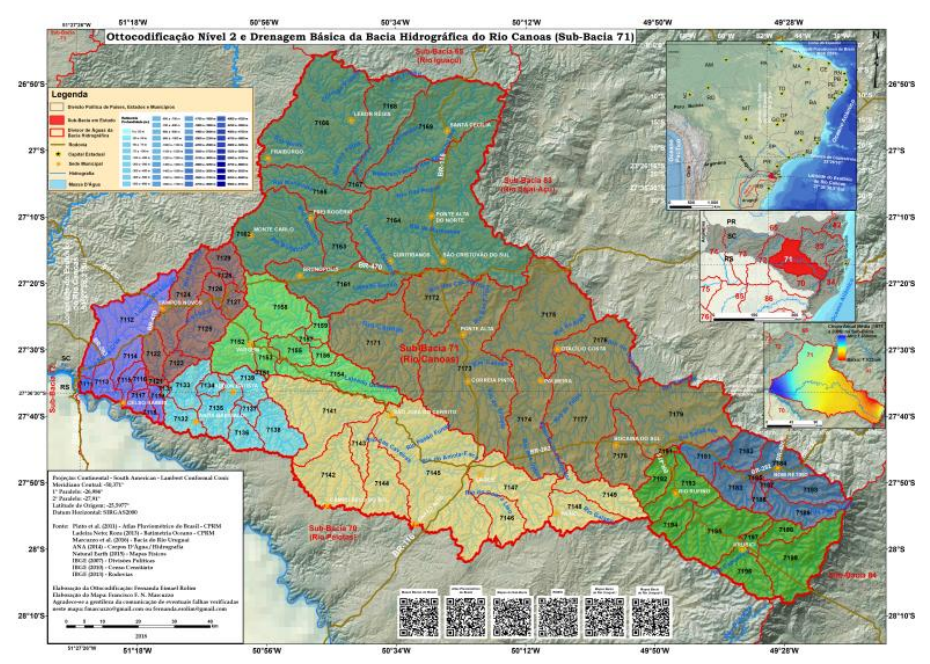

Figura 3 - Ottocodificação nível 2 e drenagem básica da bacia hidrográfica do rio Canoas.

Tabela 1 - Rio principal, área e área em relação a área total da sub-bacia 71 para nível 1 de Ottocodificação.

\begin{tabular}{clcc}
\hline $\begin{array}{c}\text { Sub- } \\
\text { bacia }\end{array}$ & \multicolumn{1}{c}{$\begin{array}{c}\text { Rio } \\
\text { principal }\end{array}$} & Área $\left(\mathbf{k m}^{2}\right)$ & $\begin{array}{c}\text { Área em relação a área da } \\
\text { sub-bacia 71 }(\%)\end{array}$ \\
\hline 71 & rio Canoas & 13460,82 & 100,00 \\
711 & rio Canoas & 524,27 & $3,89 \%$ \\
712 & - & 611,44 & $4,54 \%$ \\
713 & rio Canoas & 594,09 & $4,41 \%$ \\
714 & rio Caveiras & 2178,98 & $16,19 \%$ \\
715 & rio Canoas & 747,85 & $5,56 \%$ \\
716 & - & 3547,44 & $26,35 \%$ \\
717 & rio Canoas & 3589,41 & $26,67 \%$ \\
718 & - & 643,45 & $4,78 \%$ \\
719 & rio Canoas & 1023,85 & $7,61 \%$ \\
\hline
\end{tabular}

*Os campos onde há “-“ não foram encontrados os nomes do rio principal.

Tabela 2 - Rio principal, área e área em relação a área total da sub-bacia 71 para nível 2 de Ottocodificação. (Continua)

\begin{tabular}{clcc}
\hline Sub-Bacia & \multicolumn{1}{c}{ Rio principal } & $\begin{array}{c}\text { Área } \\
\left(\mathbf{k m}^{2}\right)\end{array}$ & $\begin{array}{c}\text { Área em Relação a Área } \\
\text { Total da Sub-Bacia 71 (\%) }\end{array}$ \\
\hline 71 & rio Canoas & $13.460,8$ & $100,00 \%$ \\
7111 & rio Canoas & 12,03 & $0,09 \%$ \\
7112 & rio Santa Cruz & 283,36 & $2,11 \%$ \\
7113 & rio Canoas & 53,82 & $0,40 \%$ \\
7114 & Lageado Passo Grande & 53,68 & $0,40 \%$ \\
7115 & rio Canoas & 33,9 & $0,25 \%$ \\
7116 & - & 19,18 & $0,14 \%$ \\
7117 & rio Canoas & 30,42 & $0,23 \%$ \\
7118 & - & 10,9 & $0,08 \%$ \\
7119 & rio Canoas & 26,74 & $0,20 \%$ \\
7121 & rio Ibicuí & 11,77 & $0,09 \%$
\end{tabular}

$\begin{array}{llcl}7122 & \text { Arroio Aguapé } & 61,9 & 0,46 \% \\ 7123 & \text { Ibicuí } & 43,13 & 0,32 \% \\ 7124 & \text { rio São João } & 181,35 & 1,35 \% \\ 7125 & \text { rio Ibicuí } & 148,27 & 1,10 \% \\ 7126 & \text { Lageado Inferninho } & 37,18 & 0,28 \% \\ 7127 & \text { rio Inferninho Grande } & 44,77 & 0,33 \% \\ 7128 & - & 12,72 & 0,09 \% \\ 7129 & - & 69,7 & 0,52 \% \\ 7131 & \text { rio Canoas } & 5,90 & 0,04 \% \\ 7132 & \text { Arroio dos Antunes } & 67,13 & 0,50 \% \\ 7133 & \text { rio Canoas } & 89,77 & 0,67 \%\end{array}$

Tabela 2 - Rio principal, área e área em relação a área total da sub-bacia 71 para nível 2 de Ottocodificação. (Continuação)

\begin{tabular}{|c|c|c|c|}
\hline $\begin{array}{l}\text { Sub- } \\
\text { Bacia }\end{array}$ & Rio principal & $\begin{array}{l}\text { Área } \\
\left(\mathbf{k m}^{2}\right)\end{array}$ & $\begin{array}{c}\text { Área em Relação a Área } \\
\text { Total da Sub-Bacia } 71(\%)\end{array}$ \\
\hline 7134 & Lageado da Derrubada & 32,9 & $0,25 \%$ \\
\hline 7135 & rio Canoas & 115,62 & $0,86 \%$ \\
\hline 7136 & - & 65,9 & $0,49 \%$ \\
\hline 7137 & rio Canoas & 23,9 & $0,18 \%$ \\
\hline 7138 & - & 129,6 & $0,96 \%$ \\
\hline 7139 & rio Canoas & 62,82 & $0,47 \%$ \\
\hline 7141 & rio Caveiras & 351,84 & $2,61 \%$ \\
\hline 7142 & - & 240,5 & $1,79 \%$ \\
\hline 7143 & rio Caveiras & 68,04 & $0,51 \%$ \\
\hline 7144 & $\begin{array}{l}\text { Lageado Mandu ou } \\
\text { Taimbé }\end{array}$ & 176,2 & $1,31 \%$ \\
\hline 7145 & rio Caveiras & 718,20 & $5,34 \%$ \\
\hline 7157 & rio Canoas & 18,88 & $0,14 \%$ \\
\hline 7158 & rio do Pinto & 202,44 & $1,50 \%$ \\
\hline 7159 & rio Canoas & 41,83 & $0,31 \%$ \\
\hline 7161 & rio dos Marombas & 306,59 & $2,28 \%$ \\
\hline 7162 & rio Taquaruçu & 384,81 & $2,86 \%$ \\
\hline 7163 & rio das Marombas & 111,16 & $0,83 \%$ \\
\hline 7164 & rio das Marombas & 1088,88 & $\begin{array}{c}8,09 \\
\%\end{array}$ \\
\hline 7165 & rio dos Correntes & 219,65 & $1,63 \%$ \\
\hline 7166 & - & 665,11 & $4,94 \%$ \\
\hline 7167 & rio dos Correntes & 20,03 & $0,15 \%$ \\
\hline 7168 & - & 252,71 & $1,88 \%$ \\
\hline 7169 & rio dos Correntes & 497,09 & $3,69 \%$ \\
\hline 7171 & rio Canoas & 462,20 & $3,43 \%$ \\
\hline
\end{tabular}




\begin{tabular}{llcl}
7172 & rio dos Cachorros & 215,02 & $1,60 \%$ \\
7173 & rio Canoas & 771,72 & $5,73 \%$ \\
7174 & rio dos Índios & 332,74 & $2,47 \%$ \\
7175 & rio Canoas & 472,28 & $3,51 \%$ \\
7176 & rio dos Desquites & 227,72 & $1,69 \%$ \\
7177 & rio Canoas & 459,18 & $3,41 \%$ \\
7178 & - & 186,33 & $1,38 \%$ \\
7179 & rio Canoas & 460,33 & $3,42 \%$ \\
7181 & rio João Paulo & 90,19 & $0,67 \%$ \\
7182 & - & 80,87 & $0,60 \%$ \\
7183 & rio João Paulo & 96,78 & $0,72 \%$ \\
7184 & rio Ponte Alta & 114 & $0,85 \%$ \\
\hline
\end{tabular}

Tabela 2 - Rio principal, área e área em relação a área total da sub-bacia 71 para nível 2 de Ottocodificação. (Conclusão)

\begin{tabular}{clcc}
\hline Sub-Bacia & \multicolumn{1}{c}{ Rio principal } & $\begin{array}{c}\text { Área } \\
\left(\mathbf{k m}^{2}\right)\end{array}$ & $\begin{array}{c}\text { Área em Relação a } \\
\text { Área Total da Sub- } \\
\text { Bacia 71 (\%) }\end{array}$ \\
\hline 7185 & rio João Paulo & 3,05 & $0,02 \%$ \\
7186 & - & 27,75 & $0,21 \%$ \\
7187 & rio João Paulo & 7,07 & $0,05 \%$ \\
7188 & rio Paraiso & 109,87 & $0,82 \%$ \\
7189 & rio Campo Novo do Sul & 113,38 & $0,84 \%$ \\
7191 & rio Canoas & 7,90 & $0,06 \%$ \\
7192 & - & 83,87 & $0,62 \%$ \\
7193 & rio Canoas & 145,07 & $1,08 \%$ \\
7194 & - & 71,07 & $0,53 \%$ \\
7195 & rio Canoas & 247,33 & $1,84 \%$ \\
7196 & rio Urubici & 117,77 & $0,87 \%$ \\
7197 & rio Canoas & 32,43 & $0,24 \%$ \\
7198 & rio dos Burgues & 52,56 & $0,39 \%$ \\
7199 & rio Canoas & 265,4 & $1,97 \%$ \\
7199 & rio Canoas & 265,48 & $1,97 \%$ \\
\hline
\end{tabular}

* Os campos onde há “-"não foram encontrados os nomes do rio principal.

Quadro 4 - Municípios presentes em cada sub-bacia para nível 1 de Ottocodificação. (Continua)

\begin{tabular}{|cc|}
\hline Sub-Bacia & Municípios com Área Territorial na SB \\
\hline & Anita Garibaldi, Orleans, Painel, Palmeira, Ponte Alta, om \\
Jardim da Serra, Caçador, Calmon, Capão Alto, Campo Belo \\
do Sul, Campos Novos, Cerro Negro, Correia Pinto Fraiburgo, \\
Ponte Alta do Norte, Santa Cecília, São Cristóvão do Sul, Taió, \\
Brunópolis, Curitibanos, Frei Rogério, Lages, Lebon Régis,
\end{tabular}

\begin{tabular}{|cc|}
\hline Sub-Bacia & Municípios com Área Territorial na SB \\
\hline 71 & Otacílio Costa, Monte Carlo, Monte Castelo, Grão Pará, Rio \\
& Fortuna, Batista, Agrolândia, Braço do Trombudo, Bocaina do \\
& Sul, Ibiam, Celso Ramos, Mirim Doce, Petrolândia, Pouso \\
& Redondo, Tangará, Rio do Campo, Rio Rufino, Urupema, \\
& Vargem, Urubici, Alfredo Wagner, Anitápolis,Bom Retiro, \\
& Chapadão do Lageado, Santa Rosa de Lima \\
711 & Campos Novos, Celso Ramos \\
712 & Campos Novo, Campos Novos, Monte Carlo, Abdon Batista, \\
713 & Ibiam, Celso Ramos, Tangará, Vargem \\
& Anita Garibaldi, Campo Belo do Sul, Campos Novos, Cerro \\
714 & Negro, São José do Cerrito, Abdon Batista, Celso Ramos \\
& Painel, Capão Alto, Campo Belo do Sul, Cerro Negro, Correia \\
& Pinto, Lages, São José do Cerrito, Abdon Batista, Bocaina do \\
& Sul, Rio Rufino, Urupema \\
\hline
\end{tabular}

Quadro 4 - Municípios presentes em cada sub-bacia para nível 1 de Ottocodificação. (Conclusão)

\begin{tabular}{|c|c|}
\hline 715 & $\begin{array}{c}\text { Campos Novos, Cerro Negro, Brunópolis, São José do Cerrito, } \\
\text { Abdon Batista, Vargem }\end{array}$ \\
\hline 716 & $\begin{array}{l}\text { Ponte Alta, Caçador, Calmon, Campos Novos, Fraiburgo, } \\
\text { Ponte Alta do Norte, Santa Cecília, São Cristóvão do Sul, Taió, } \\
\text { Brunópolis, Curitibanos, Frei Rogério, Lebon Régis, Monte } \\
\text { Carlo, Monte Castelo, Mirim Doce, Tangará, Rio do Campo }\end{array}$ \\
\hline 717 & $\begin{array}{c}\text { Painel, Palmeira, Ponte Alta, Correia Pinto, São Cristóvão do } \\
\text { Sul, Brunópolis, Curitibanos, Lages, Otacílio Costa, São José } \\
\text { do Cerrito, Braço do Trombudo, Bocaina do Sul, Mirim Doce, } \\
\text { Petrolândia, Pouso Redondo, Bom Retiro, Chapadão do } \\
\text { Lageado }\end{array}$ \\
\hline 718 & $\begin{array}{c}\text { Bocaina do Sul, Rio Rufino, Urubici, Alfredo Wagner, } \\
\text { Anitápolis, Bom Retiro }\end{array}$ \\
\hline 719 & $\begin{array}{c}\text { Orleans, Painel, Bom Jardim da Serra, Grão Pará, Rio Fortuna, } \\
\text { Bocaina do Sul, Rio Rufino, Urupema, Urubici, Anitápolis, } \\
\text { Bom Retiro, Santa Rosa de Lima }\end{array}$ \\
\hline
\end{tabular}

Quadro 5 - Municípios presentes em cada sub-bacia para nível 2 de Ottocodificação. (Continua)

\begin{tabular}{|cl|}
\hline Sub-Bacia & Municípios com Área Territorial na SB \\
\hline 7111 & Campos Novos, Celso Ramos \\
7112 & Campos Novos, Celso Ramos \\
7113 & Campos Novos, Celso Ramos \\
7114 & Campos Novos, Celso Ramos \\
7115 & Campos Novos, Celso Ramos \\
7116 & Campos Novos \\
7117 & Campos Novos, Celso Ramos \\
7118 & Campos Novos, Celso Ramos \\
7119 & Campos Novos, Celso Ramos
\end{tabular}




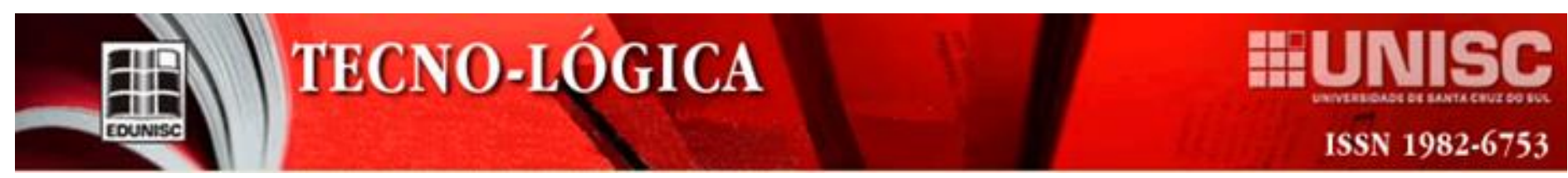

\begin{tabular}{|ll|}
7121 & Campos Novos \\
7122 & Campos Novos \\
7123 & Campos Novos \\
7124 & Campos Novos, Ibiam, Tangará \\
7125 & Campos Novos, Vargem \\
7126 & Campos Novos \\
7127 & Campos Novos, Vargem \\
7128 & Campos Novos \\
7129 & Campos Novos, Monte Carlo, Tangará \\
7131 & Anita Garibaldi, Campos Novos, Celso Ramos \\
\hline
\end{tabular}

Quadro 5 - Municípios presentes em cada sub-bacia para nível 2 de Ottocodificação (continuação)

\begin{tabular}{|c|c|}
\hline Sub-Bacia & Municípios com Área Territorial na SB \\
\hline 7132 & Anita Garibaldi, Campos Novos, Celso Ramos \\
\hline 7133 & Anita Garibaldi, Campos Novos, Abdon Batista \\
\hline 7134 & Abdon Batista \\
\hline 7135 & Anita Garibaldi, Abdon Batista \\
\hline 7136 & Anita Garibaldi, Cerro Negro, Abdon Batista \\
\hline 7137 & Anita Garibaldi, Cerro Negro, Abdon Batista \\
\hline 7138 & Anita Garibaldi, Campo Belo do Sul, Cerro Negro \\
\hline 7139 & $\begin{array}{l}\text { Anita Garibaldi, Cerro Negro, São José do Cerrito, } \\
\text { Abdon Batista, São José do Cerrito }\end{array}$ \\
\hline 7141 & $\begin{array}{l}\text { Campo Belo do Sul, Cerro Negro, São José do } \\
\text { Cerrito }\end{array}$ \\
\hline 7142 & $\begin{array}{l}\text { Campo Belo do Sul, Cerro Negro, São José do } \\
\text { Cerrito }\end{array}$ \\
\hline 7143 & Campo Belo do Sul, São José do Cerrito \\
\hline 7144 & $\begin{array}{l}\text { Capão Alto, Campo Belo do Sul, Lages, São José do } \\
\text { Cerrito }\end{array}$ \\
\hline 7145 & $\begin{array}{l}\text { Capão Alto, Correia Pinto, Lages, São José do } \\
\text { Cerrito }\end{array}$ \\
\hline 7146 & Lages \\
\hline 7147 & Painel, Lages \\
\hline 7148 & Painel, Lages \\
\hline 7149 & Painel, Lages, Bocaina do Sul, Rio Rufino, Urupema \\
\hline
\end{tabular}

\begin{tabular}{|c|c|}
\hline 7151 & São José do Cerrito, Abdon Batista \\
\hline 7152 & $\begin{array}{l}\text { Campos Novos, São José do Cerrito, Abdon Batista, } \\
\text { Vargem }\end{array}$ \\
\hline 7153 & São José do Cerrito, Vargem \\
\hline 7154 & São José do Cerrito, Vargem \\
\hline 7155 & São José do Cerrito, Vargem \\
\hline 7156 & São José do Cerrito, Vargem \\
\hline 7157 & Brunópolis, São José do Cerrito, Vargem \\
\hline 7158 & Campos Novos, Brunópolis, Vargem \\
\hline 7159 & Brunópolis, Curitibanos, São José do Cerrito \\
\hline
\end{tabular}

Quadro 5 - Municípios presentes em cada sub-bacia para nível 2 de Ottocodificação (continuação)

\section{Sub-Bacia Municípios com Área Territorial na SB}

7161 Campos Novos, Brunópolis, Curitibanos, Frei Rogério

7162 Campos Novos, Fraiburgo, Brunópolis, Curitibanos, Frei Rogério, Monte Carlo, Tangará

7163 Curitibanos, Frei Rogério

Ponte Alta, Ponte Alta do Norte, Santa Cecília, São

7164 Cristóvão do Sul,Taió, Curitibanos, Frei Rogério, Mirim Doce, Rio do Campo

7165 Fraiburgo, Curitibanos, Frei Rogério

7166 Caçador, Calmon, Fraiburgo, Rio das Antas, Lebon Régis

7167 Fraiburgo, Curitibanos, Lebon Régis

7168 Santa Cecília, Lebon Régis

7169 Santa Cecília, Curitibanos, Lebon Régis, Monte Castelo, Rio do Campo

7171 Correia Pinto, Brunópolis, Curitibanos, São José do Cerrito

7172 Ponte Alta, Correia Pinto, São Cristóvão do Sul, Curitibanos

Ponte Alta, Correia Pinto, São Cristóvão do Sul, Lages, São José do Cerrito

$7174 \quad$ Palmeira, Ponte Alta, Correia Pinto, Lages 


$\begin{array}{ll}7175 & \begin{array}{l}\text { Palmeira, Ponte Alta, Correia Pinto, São Cristóvão do } \\ \text { Sul, Otacílio Costa, Mirim Doce, Pouso Redondo }\end{array} \\ 7176 & \text { Otacílio Costa, Agrolândia, Braço do Trombudo } \\ 7177 & \text { Painel, Palmeira, Lages, Otacílio Costa, Bocaina do Sul } \\ 7178 & \text { Painel, Otacílio Costa, Bocaina do Sul } \\ 7179 & \begin{array}{l}\text { Otacílio Costa, Bocaina do Sul, Petrolândia, Bom Retiro, } \\ \text { Chapadão do Lageado }\end{array} \\ 7181 & \text { Bocaina do Sul, Bom Retiro } \\ 7182 & \text { Bom Retiro } \\ 7183 & \text { Rio Rufino, Urubici, Bom Retiro }\end{array}$

Quadro 5 - Municípios presentes em cada sub-bacia para nível 2 de Ottocodificação (conclusão)

\begin{tabular}{|c|c|}
\hline Sub-Bacia & Municípios com Área Territorial na SB \\
\hline 7184 & Alfredo Wagner, Bom Retiro \\
\hline 7185 & Bom Retiro \\
\hline 7186 & Urubici, Bom Retiro \\
\hline 7187 & Bom Retiro \\
\hline 7188 & Alfredo Wagner, Bom Retiro \\
\hline 7189 & Urubici, Alfredo Wagner, Anitápolis, Bom Retiro \\
\hline 7191 & Bocaina do Sul, Bom Retiro \\
\hline 7192 & Painel, Bocaina do Sul, Rio Rufino, Bom Retiro \\
\hline 7193 & Painel, Bocaina do Sul, Rio Rufino, Bom Retiro \\
\hline 7194 & Rio Rufino, Urupema \\
\hline 7195 & Rio Rufino, Urupema, Urubici, Bom Retiro \\
\hline 7196 & Bom Jardim da Serra, Urubici \\
\hline 7197 & Urubici, Bom Retiro \\
\hline 7198 & Urubici, Bom Retiro \\
\hline 7199 & $\begin{array}{l}\text { Orleans, Bom Jardim da Serra, Grão Pará, Rio Fortuna, } \\
\text { Urubici, Anitápolis, Bom Retiro, Santa Rosa de Lima }\end{array}$ \\
\hline
\end{tabular}

\subsection{Precipitação Pluviométrica}

Nota-se na Figura 4 que os volumes pluviométricos maiores encontra-se na região oeste da bacia 71 , sendo os municípios em destaque são Anita Garibaldi, Celso Ramos e Campos Novos.

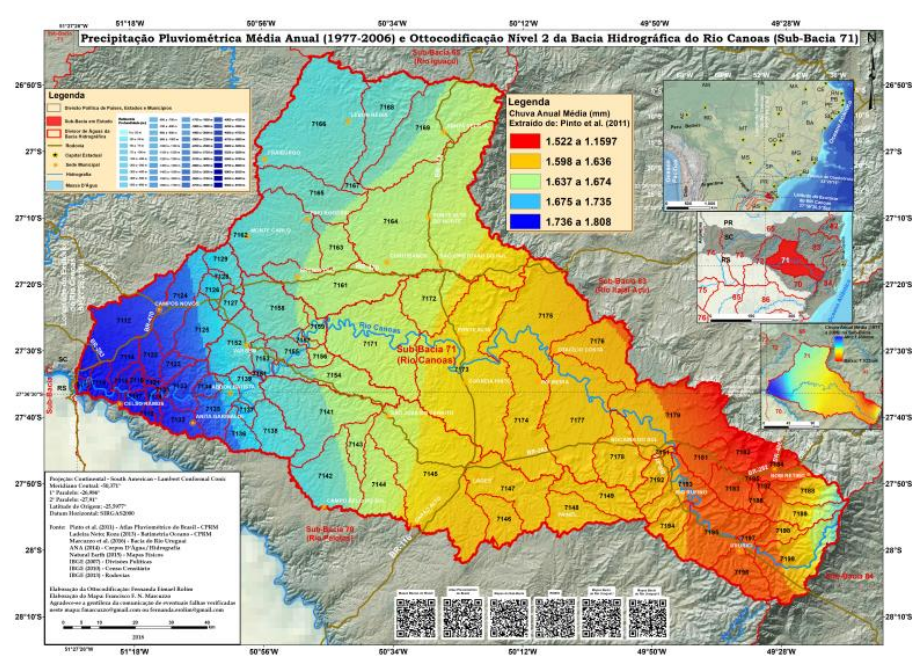

Figura 4 - Precipitação pluviométrica média anual (1977 e 2006) e ottocodificação da bacia hidrográfica do rio Canoas (sub-bacia 71).

As sub-bacias ottocodificadas de nível 2 que abrange a maior pluviosidade, isto é, entre $1.736 \mathrm{~mm}$ a $1.808 \mathrm{~mm}$ são representativas as sub-bacias 7112,7113 e 711 . O máximo volume de precipitação pluviométrica anual média registrada na bacia hidrográfica do rio Canoas, segundo Pinto et al. [17] é $1.808 \mathrm{~mm}$ e a mínima precipitação anual média de $1.522 \mathrm{~mm}$, sendo assim uma amplitude de $286 \mathrm{~mm}$.Os municípios onde os volumes pluviométricos são menores, caracterizando, portanto, como regiões secas encontra-se ao leste da bacia 71 que são as cidades de Urubici e Bom Retiro. Algumas sub-bacias ottocodificadas de nível 2 as quais podem ser representativas dessas localidades mais áridas são as 7182, 7184 e 7197.

\subsection{Altimetria}

O relevo da sub-bacia 71 apresentou as maiores altitudes na região leste, como mostra a Figura 5, as sub-bacias representativas das regiões mais altas são as 7194, 7198 e 7189, os municípios exemplificativamente são, Urupema, Bom Retiro e Anitápolis, respectivamente, as quais estão em coloração esbranquiçada no mapa. A máxima altitude encontrada é $1.824 \mathrm{~m}$. Em relação às menores altitudes localizam-se na região oeste, as sub-bacias representativas ottocodificadas são 7121, 7113, os municípios os quais retratam a baixa altitude são Campos Novos e Celso Ramos, respectivamente. Nota-se que são as sub-bacias próximas ao exutório, o que a torna coerente a analise, visto que 
as água pluviométricas se desenvolvem ao longo do terreno das altas para baixas altitudes. A menor cota encontrada é de $751 \mathrm{~m}$.

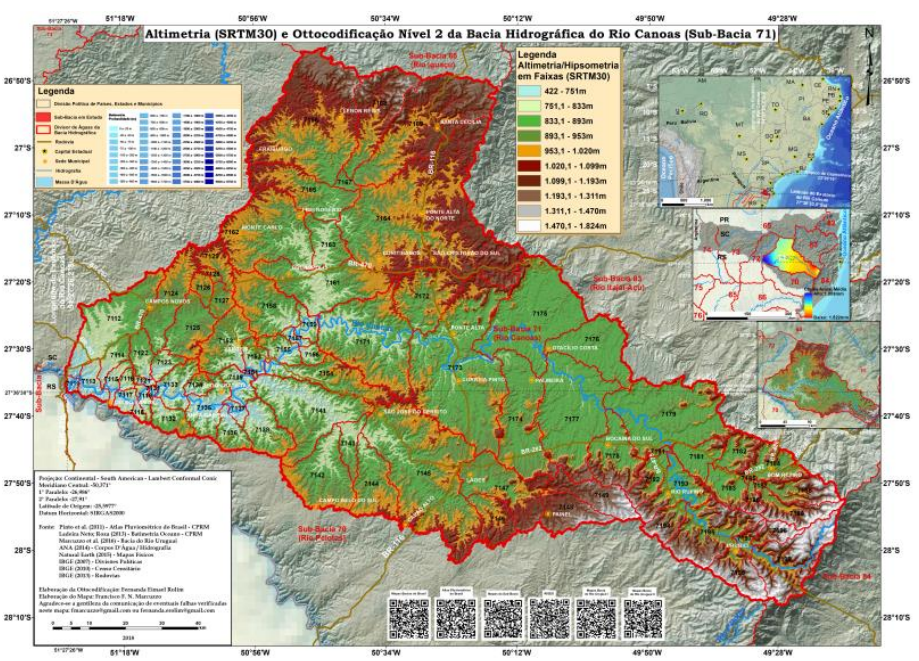

Figura 5 - Altimetria (SRTM30) e ottocodificação nível 2 da bacia hidrográfica do rio Canoas (sub-Bacia 71)

\section{Conclusão}

$\mathrm{O}$ desenvolvimento deste trabalho permite o conhecimento da ottocodificação desenvolvido por Otto Pfafstetter, aplicada à bacia do rio Canoas, classificada segundo ANA como sub-bacia 71, e devido ao seu ordenamento e o seu sistema de numeração entre as sub-bacias, torna-se mais direcionada e simplificada diversas conjecturas ambientais, como as análises de altimetria e dos volumes de precipitações na região de estudo, embora não tenha sido o enfoque deste estudo, a classificação desenvolvida contribui para um melhor entendimento do funcionamento da bacia e do meio ambiente, além de servir de subsidio para as modelagens hidrológicas, para que tenha uma sequência a seguir, facilitando, portanto, cálculos computacionais. Finalmente, as classificações feitas podem servir como dados de entrada para futuras aplicações em outros tipos modelagem da engenharia hidrológica, facilitando assim o trabalho do pré-processamento.

\section{Agradecimentos}

Os autores agradecem a CPRM/SGB (Companhia de Pesquisa Recursos Minerais / Serviço Geológico do Brasil Empresa Pública do Ministério de Minas e Energia) pelo fomento que viabilizou o desenvolvimento deste trabalho.

\section{OTTOCODING AND ALTIMETRIC ANALYSIS AND PRECIPITATION CANOAS WATERSHED ON THE BORDER BETWEEN RIO GRANDE DO SUL AND SANTA CATARINA}

ABSTRACT: Develop a good parsing in large watershed is a challenge, since arranging a system easy to understand for the researcher is feasible to create procedures that discretize the water catchment area. In this context, the present study had as objective ottocoding Canoas watershed (71 sub-basin) in two levels of encoding, using the methodology developed by Otto Pfafstetter in the year 1989. Thus, this methodology allows us to develop a targeted and concise analysis of the altimetry and the volumes of rainfall. The procedure had computational program support of GIS (geographic information Systems), in particular ArcGIS 10.2, digital template of elevation SRTM, with a resolution of $30 \mathrm{~m}$. Gathering all this information arrive the results of geodetic coordinates of the outfall area, as well as municipalities and the main river of each sub-basin. The ottocoded sub-basin with greater area is the 717 , with approximately $3,589.41 \mathrm{~km}^{2}$ classified as level 1 , and your percentage in relation to the Sub-basin 71 is $26.67 \%$ in relation the ottocoded sub-basin of smaller area, the 7185 , is classified as level 2 , presents an area around $3,06 \mathrm{~km}^{2}$ with a percentage in relation to the Sub-basin 71 of $0.02 \%$. In all subbasins were delimited 90 , and 9 of them are level 1 and 81 as level 2 .

Keywords: Sub-bacia 71. Otto Pfafstetter. Uruguay River basin.

\section{Referências}

[1] BRASIL. Agência Nacional de Águas. Inventário das estações fluviométricas. 2. ed. Brasília, 2009. Disponível em: <http://arquivos.ana.gov.br/infohidrologicas/ InventariodasEstacoesFluviometricas.pdf >. Acesso em: 18 out. 2018

[2] BRASIL. Agência Nacional de Águas. Hidroweb: Sistema de informações hidrológicas. Disponível em:〈http://www.snirh.gov.br/hidroweb〉. Acesso em: 18 out. 2018.

[3] BRASIL, Agência Nacional de Águas. Codificação De Bacias Hidrográficas Pelo Método De Otto Pfafstetter. 2018. Disponível em: <https://cap acitacao.ead.unesp.br/dspace/handle/ana/104> Acesso em: 23 mai. 2018

[4] BUARQUE, D.C.; PAZ, A.R.; COLLISCHONN, W. (2008). Extração automática de parâmetros físicos de bacias hidrográficas a partir do MNT para utilização em modelos hidrológicos. In: Simpósio Sul-Sudeste de Recursos Hídricos, Rio de Janeiro (RJ), ABRH. Disponível em:<http://www.ct.ufpb.br/ ad rianorpaz/artigos/Buarque_et_al_SRHSulSud_2008.pdf $>$. Acesso em: 13 ago. 2018

[5] COLLISCHONN, W.; DORNELLES, F. Hidrologia para engenharia e ciências ambientais. Edição 2- revisada e ampliada. ed. Porto Alegre: Associação Brasileira de Recursos Hídricos, 2015. 
[6] EARTH EXPLORER. Desenvolvido por U.S. Department of the Interior U.S. Geological Survey, 2014. Permit your search in area: type in an address or place name, enter coordinates or click the map to define your search area (for advanced map tools, view the help documentation), and/or choose a date range. Disponível em: 〈http://earthexplorer.usgs.gov>. Acesso em: 10 ago. 2018.

[7] ESRI - Environmental Systems Research Institute. ArcGIS. Sistema de Informação Geográfica para área de trabalho de computador, versão 10.3. 2015. Disponível em: <https://www.arcgis.com/features/>. 09 abr. 2013

[8] GALVÃO, W. S.; MENESES, P. R. Avaliação dos sistemas de classificação e codificação das bacias hidrográficas brasileiras para fins de planejamento de redes hidrométricas. In: SIMPÓSIO BRASILEIRO DE SENSORIAMENTO REMOTO, 12. (SBSR), 2005, Goiânia. Anais... São José dos Campos: INPE, 2005. p. 2511 a 2518. Disponível em: 〈http://urlib.net/ltid.inpe.br/sbsr/2004/11.21.01.26>. Acess ado em: 13 Ago. 2018.

[9] GOULARTE, E. R. P.; MARCUZZO, F. F. N.; MACEDO, F. C. SRTM 1-ARC interpolado e o SRTM 3-ARC na delimitação automática da Sub-Bacia do Alto Meia Ponte em Goiás. In: SIMPÓSIO DOS RECURSOS HIDRICOS DO NORDESTE, 13., 2016, Aracaju. Anais... Aracaju: ABRH, 2016. Disponível em: <http://rigeo.cprm.gov.br/jspui/handle/doc/17190>. Acesso em: 17 Out. 2018.

[10] GUIMARÃES, G. M.; ALMEIDA,D. B.; MARCUZZO, F. F. N. SIG na construção de diagramas unifilares das estações F, FD, P, Pr além das UHE, PCH, CGH das sub-bacias 80 a 84 na bacia hidrográfica do Atlântico - Trecho Sudeste. In: XVII Simpósio Brasileiro de Sensoriamento Remoto, Santos, Brasil, 7 a 10 de abril de 2017, Anais... INPE, v. 1, 2017. Disponível em: <https://drive.go ogle.com/file/d/0B6T7sNg_aVgONIBPSENtQWtqSzQ/view?usp=sharing >. Acesso em: 17 out. 2018

[11] INSTITUTO BRASILEIRO DE GEOGRAFIA E ESTATÍSTICA. Área Territorial Brasileira. [Brasília], S.D. Disponível em: <http://www.ibge.gov.br/ho me/geociencias/areaterritorial/principal.shtm $>$. Acesso em: 18 out. 2018.

[12] JENSON, S.K., DOMINGUE, J.O. Extracting topographic structure from digital elevation data for geographic information system analysis. Photogrammetric Engineering and Remote Sensing, v. 54, n. 11, p. 1593 1600, 1988.Disponível em: <https://www.asprs.org/wpcontent/uploads/pers/1988journal/nov/1988_nov_159 3-1600.pdf > Acesso em: 13 ago. 2018

[13] KOEFENDER, A.; MARCUZZO, F. F. N. Análise de diferentes MDE no calculo de área de drenagem e perímetro de estações fluviométricas na sub-bacia 76. In: Simpósio Brasileiro de Recursos Hídricos, 21, 2015, Brasília. Anais... Porto Alegre: ABRH, 2015. p. 1 a 8. Disponível em: <https://drive.google.com/file/d/0 B6T7sNg aVgOZIN4UF9WdVFHSWc/view? usp=sharing $>$. Acesso em: 17 out. 2018.

[14] MARCUZZO, F. F. N. Bacias hidrográficas e regiões hidrográficas do Brasil: cálculo de áreas, diferenças e considerações. In: SIMPÓSIO BRASILEIRO DE RECURSOS HÍDRICOS, 22., 2017, Florianópolis. Anais... Florianópolis: ABRH, 2017. Disponível em: http://rigeo.cprm.gov.br/jspui/handle/doc/18492. Acesso em: 18 out. 2018

[15] MARCUZZO, F. F. N. Mapas e opções de divisão territorial do estado do Rio Grande do Sul por bacias hidrográficas. In: CONGRESSO BRASILEIRO DE GEOLOGIA, 49., 2018, Rio de Janeiro. Anais... Rio de Janeiro: SBG, 2018. Disponível em: 〈http://rigeo.cprm.gov.br/jspui/handle/doc/19906〉. Acesso em: 18 out. 2018.

[16] MARCUZZO, F. F. N. Bacia hidrográfica do rio Uruguai: altimetria e áreas. In: XXII, SIMPÓSIO BRASILEIRO DE RECURSOS HÍDRICOS, 2017, Florianópolis/SC. Anais... Porto Alegre: ABRH, 2017, p. 1 a 7. CDROM. Disponível em: <http://rigeo.cprm.gov.br/jspui/handle/doc/18489> Acesso em: 24 abr. 2018.
[17] MARCUZZO, F. F. N.; CARDOSO, M. R. D.; PINTO FILHO, R. F.; ROMERO, V. Caracterização hidromorfológica da bacia do vale do itajaí, 2011. In: SIMPÓSIO BRASILEIRO DE RECURSOS HÍDRICOS, 19., 2011, Maceió. Anais... Maceió: ABRH, 2011. Disponível em:http://rigeo.cprm.gov.br/jspui/hand le/doc/17404>. Acesso em 14 ago. 2018

[18] MARCUZZO, F. F. N.; SOUZA, C. J. R.; ALMEIDA, D. B. Bacia hidrográfica internacional do rio Uruguai e consistência dos seus divisores de água na escala 1:3.000. In: CONGRESSO BRASILEIRO DE GEOLOGIA, 48., 2016, Porto Alegre. Anais... São Paulo: SBG, 2016 Disponível em: <http://rigeo.cprm.g ov.br/jspui/handle/doc/17127> . Acesso em: 8 out. 2018.

[19] MELATI, M. D.; MARCUZZO, F. F. N. Modelos digitais de elevação na delimitação automática das sub-bacias do rio Taquari-Antas no Rio Grande do Sul. In: Simpósio Brasileiro de Sensoriamento Remoto, 17. (SBSR), 2015, Foz do Iguaçu, PR. Anais... São José dos Campos: INPE, 2015. 1 DVD. Disponível: <http://www.dsr.inpe.br/sbsr2015/files/p0075.pdf>. Acesso em: 17 out. 2018

[20] PFAFSTETTER, O. Classificação de bacias hidrográficas: metodologia de codificação. Rio de Janeiro, RJ: Departamento Nacional de Obras de Saneamento, 1989. (Manuscrito não publicado). Disponível em: <https://drive.google.com/file/

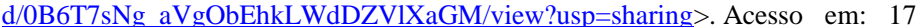
Out. 2018.

[21] ROSIM, S.; MONTEIRO, A. M. V.; RENNÓ, C. D.; SOUZA, R. C. M.; SOARES, J. V. TERRAHIDRO - Uma plataforma computacional para o desenvolvimento de aplicativos para a análise integrada de recursos hídricos. In: SIMPÓSIO BRASILEIRO DE SENSORIAMENTO REMOTO, 11. (SBSR), 2003. Anais... Belo Horizonte/MG: INPE, 2003. p. 2589 - 2596. Disponível em: <http://urlib.net/ltid.inpe.br/sbsr/2002/11.17.20.15>. Acesso em: 8 out. 2018.

[22] SILVA, N. S.; RIBEIRO, C. A. A. S.; BARROSO, W. R.; RIBEIRO. P. E. A. R.; SOARES. P. V.; SILVA. E. Sistema de ottocodificação modificado para endereçamento de redes hidrográficas. Rev. Árvore, Viçosa, v. 32, n. 5, p. 8918 97, Oct. 2008. Disponível em: < http://www.scielo.br/scielo.php?script=sci_artte xt\&pid=S0100-67622008000500014\&lng=en\&nrm=iso> Acesso em: 18 out. 2018

[23] SNYDER, J. P. Map projections: A working manual (US Geological Survey Professional Paper 1395): Washington. US Government Printing Office. [S.1.]: [s.n.], 1987. p. 397. Disponível em: < https://doi.org/10.3133/pp1395> Acesso em 8 out. 2018.

[24] TEIXEIRA, A. D. A. Manual de Construção da Base Hidrográfica ottocodificada da ANA, Brasília, 2007. 150. Disponível em: $<$ http://metadados.ana.gov.br/geonetwork/srv/en/resources.get?id=47\&fname=ma nual base ottocodificada.pdf\&access=private>. Acesso em 8 de out. 2018.

[25] TEIXEIRA, A. D. A. Ottocodificação estendida e inteligência hidrográfica em banco de dados geográficos. 2012. xi, 425 f., il. Tese (Doutorado em Geociências Aplicadas). Universidade de Brasília, Brasília, 2012..Disponível em: <http://repos itorio.unb.br/handle/10482/11181>. Acesso em: 8 de out. 2018. 